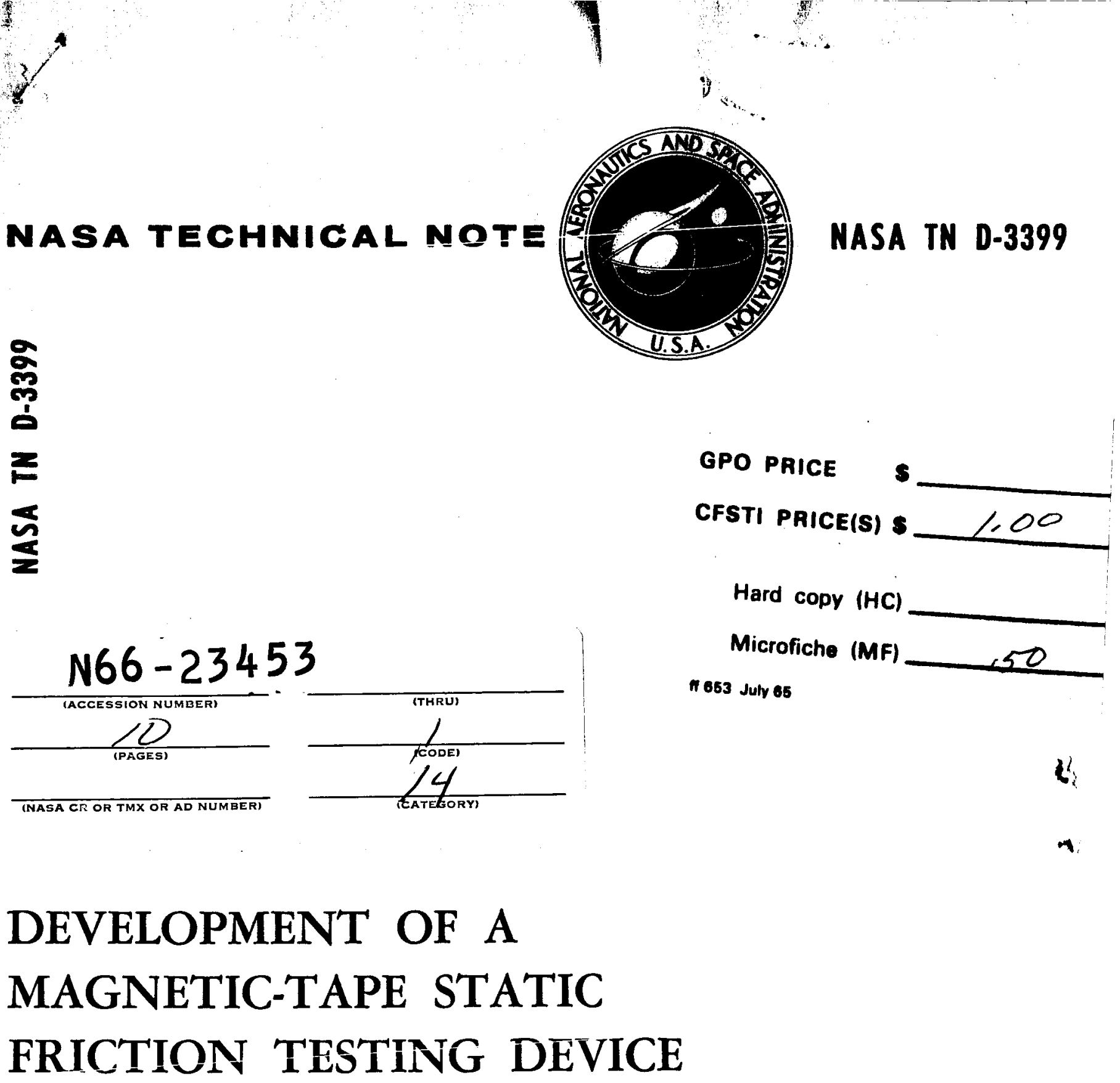

by P. T. Cole

Goddard Space Flight Center

Greenbelt, $M d$.

NATIONAL AERONAUTICS AND SPACE ADMINISTRATION - WASHINGTON, D. C. - APRIL 1966 


\section{DEVELOPMENT OF A MAGNETIC-TAPE STATIC FRICTION TESTING DEVICE By P. T. Cole}

Goddard Space Flight Center Greenbelt, Md. 
ABSTRACT

$2 \div \div 3$

A technique for determining the coefficient of friction of various materials used in magnetic tape formulation is discussed. Results are obtained which show the increased possibilities of profiling friction characteristics of these materials by the use of a device which allows of accurate, continuous measurement of static friction.

deritir

ii 
CONTENTS

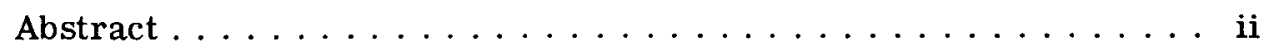

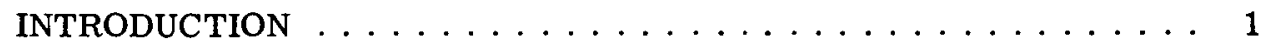

DESCRIPTION OF TEST DEVICE .............. 1

MEASURING TECHNIQUE .................. 2

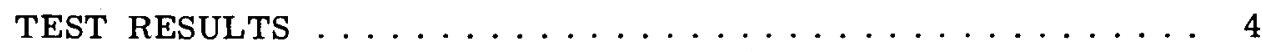

CONCLUSIONS $\ldots \ldots \ldots \ldots \ldots \ldots \ldots \ldots \ldots \ldots$

ACKNOWLEDGMENTS $\ldots \ldots \ldots \ldots \ldots \ldots \ldots \ldots \ldots \ldots \ldots$

References ........................ 6 


\title{
DEVELOPMENT OF A MAGNETIC-TAPE STATIC FRICTION TESTING DEVICE
}

\author{
by \\ P. T. Cole \\ Goddard Space Flight Center
}

\section{INTRODUCTION}

The coefficient of friction of some materials varies sufficiently with their environment to be used as an indicator of the physical stability of the material. A major impediment to the evaluation of materials' characteristics at high temperature has been an inability to obtain numerical measurements of their physical properties.

Conventionally, the coefficient of friction is treated as a constant for a given combination of materials. For many spacecraft design applications the variation of the friction coefficient must be considered. The materials of interest in this report are the various combinations of materials used in magnetic tape formulations.

Recent tape friction testing at GSFC has yielded new information, and also a possible test procedure which should facilitate obtaining knowledge relevant to tape behavior with respect to its environment. This procedure is based on the hypothesis developed by Warren Clement of the Jet Propulsion Laboratory that static friction testing of tape, after its being exposed to heat, may provide a measurement of physical stability and resistance to wear (Reference 1).

\section{DESCRIPTION OF TEST DEVICE}

The basic device is capable of measuring static or kinetic friction. However, the preliminary efforts have been directed towards the measure of static friction.

Figure 1 is a drawing of the test device. A sample of tape is clamped at the upper end to the active end of the cantilever spring containing a strain gage. The strain gage spring is mounted to the moving member of a motor-driven lead-screw mechanism. The tape, with a precision weight secured to the lower end, is suspended over a rounded-face metal block. Various film materials can be wrapped around the metal block and held in tension by a weight. For tape-to-metal test, of course, the block can be constructed of the metal desired. A thermocouple is embedded in the metal block close to the test surfaces. 


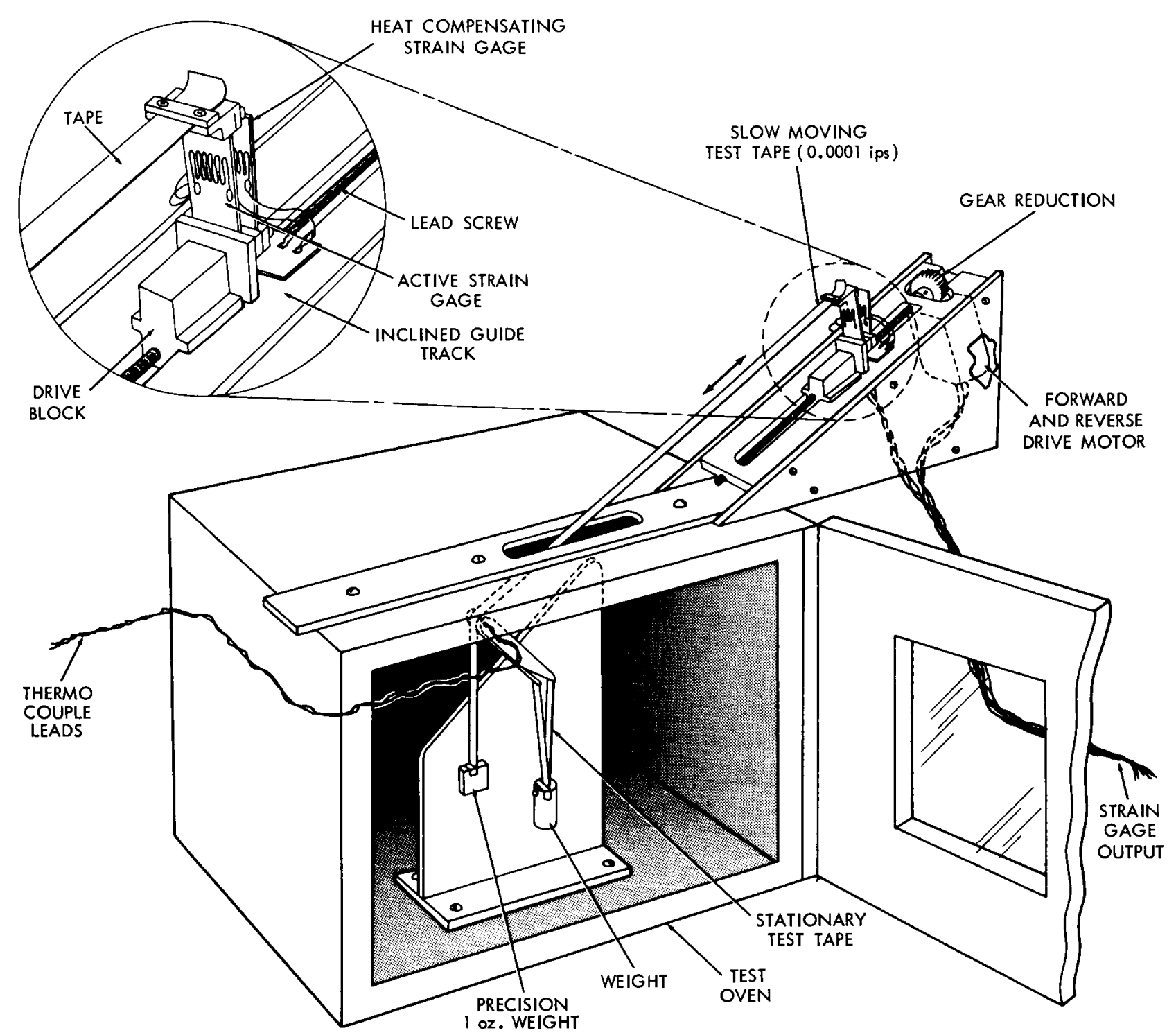

Figure 1-Drawing of the static friction testing device.

\section{MEASURING TECHNIQUE}

Static friction (limiting friction) is normally determined by the measure of impending motion when all conditions of equilibrium of limiting friction and impending motion are satisfied. Since impending motion is an applied force without motion but of sufficient force to cause motion, the force measured when motion ensues is assumed to be the value of impending motion. Previous static-friction measuring devices either directly or indirectly have measured the force when motion occurred. This has resulted in a one-shot measurement of static friction, since, once uncontrolled motion ensues, the conditions of equilibrium are not satisfied. The goal for this testing device was to achieve continuous measurement of static friction without resetting, readjustment, 
or handling of the test samples. It was felt that this could be achieved with the test sample in continuous motion, provided that the test sample velocities were extremely low. This theory is supported by Jenkin's experiments (Reference 2) which showed that kinetic friction increases as velocity decreases, and passes without discontinuity intú that of static friction. Since no numerical guide lines were available, it was necessary to establish a suitable velocity by empirical means to achieve continuous static measurement.

Test results indicate that a relative velocity in the order of 0.0001 ips is adequate to achieve sustained static friction measurement. When the moving member of the lead screw mechanism (Figure 1) is moved upward at this rate during test conditions, the strain gage output will rise to a maximum value and remain there. It is felt, at least for practical purposes, this is where the coefficients of kinetic and static friction have assumed the same value.

The strain gage output is amplified, calibrated, and recorded to represent the force in ounces. This results in the direct measurement of the friction load plus the suspended weight. The coefficient of friction for this configuration is derived by the following analysis.

Figure 2 shows the relationship between the belt tensions and the angle subtended by the belt active arc as shown by the equation

$$
\frac{\mathrm{T}_{1}}{\mathrm{~T}_{2}}=\mathrm{e}^{\mu \beta},
$$

where $\mu=$ coefficient of friction.

Solving for $\mu$,

$$
\mu=\frac{\ln \left(\mathrm{T}_{1} / \mathrm{T}_{2}\right)}{\beta}
$$

When the ratio $T_{1} / T_{2}$ reaches a maximum value the angle $\beta$ reaches a maximum value and is equal to the angle $\alpha$. Thus

$$
\mu=\frac{\ln \left(\mathrm{T}_{1} / \mathrm{T}_{2}\right)_{\max }}{\alpha} .
$$

The above relationship applied to the friction testing device discussed herein and shown in Figure 3 yields

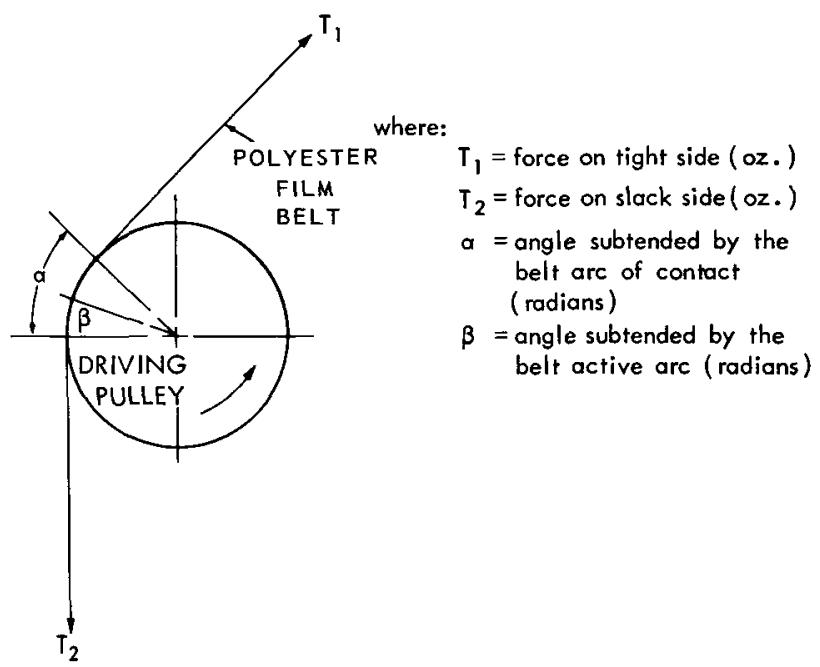

Figure 2-Pulley-belt free body diagram.

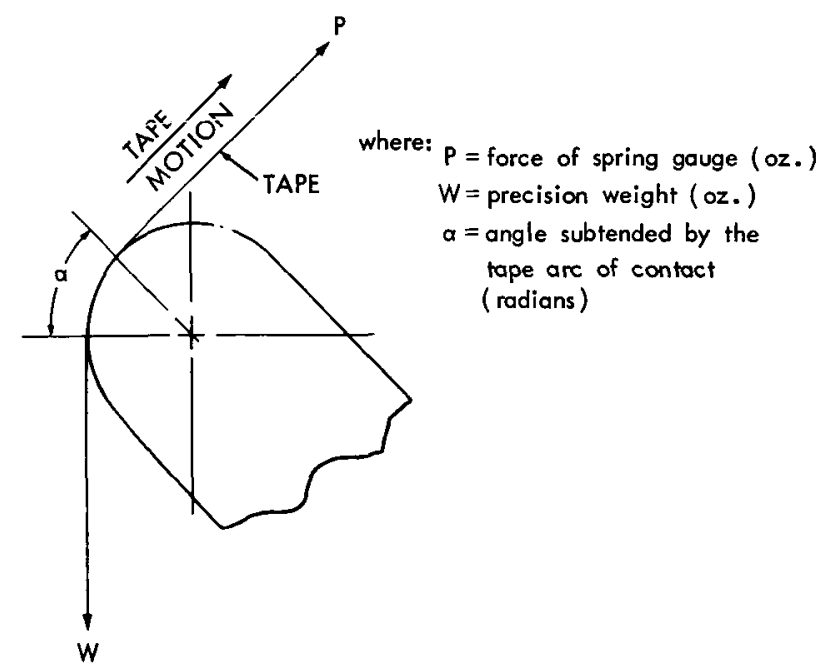

Figure 3-Friction testing device equivalent to pulley-free body diagram. 


$$
\begin{aligned}
\mathrm{T}_{1} & =\mathrm{P}, \\
\mathrm{T}_{2}=\mathrm{W} & =\text { constant }, \\
\left(\frac{\mathrm{T}_{1}}{\mathrm{~T}_{2}}\right)_{\text {max }} & =\left(\frac{\mathrm{P}_{\mathrm{max}}}{\mathrm{W}}\right),
\end{aligned}
$$

and

$$
\mu \quad \frac{\ln \left(\frac{P_{\max }}{W}\right)}{a} .
$$

If the angle $\alpha$ is set equal to one radian and the value of $w$ is selected at one oz. the equation further reduces to

$$
\mu \sim \ln _{\max }
$$

where $P_{\text {max }}$ is measured in oz.

The test device can be operated in a controlled environmental chamber. The static friction of magnetic tape and other materials can now be measured with reference to varying environmental conditions. Tests discussed in this report have been limited to friction measurements of magnetic tape at temperatures from $20^{\circ} \mathrm{C}$ to $120^{\circ} \mathrm{C}$.

\section{TEST RESULTS}

Test results are presented for the purpose of illustrating the friction versus temperature profiling capability of the device. Detailed analysis of the data will not be attempted at this time. However, some preliminary results will be presented.

Figure $4 \mathrm{a}$ is the result of a polyester film-against-film test plotted in terms of coefficient of static friction versus temperature. Figure $4 \mathrm{~b}$ is the manufacturer's data for the same film, plotting tensile strength versus temperature. The two curves are presented to show a possible correlation between friction and tensile strength. The documented data for tensile strength vs. temperature indicate a "transition temperature" at approximately 80 " C. Note that the coefficient of friction curve slope changes radically at about the same temperature. 


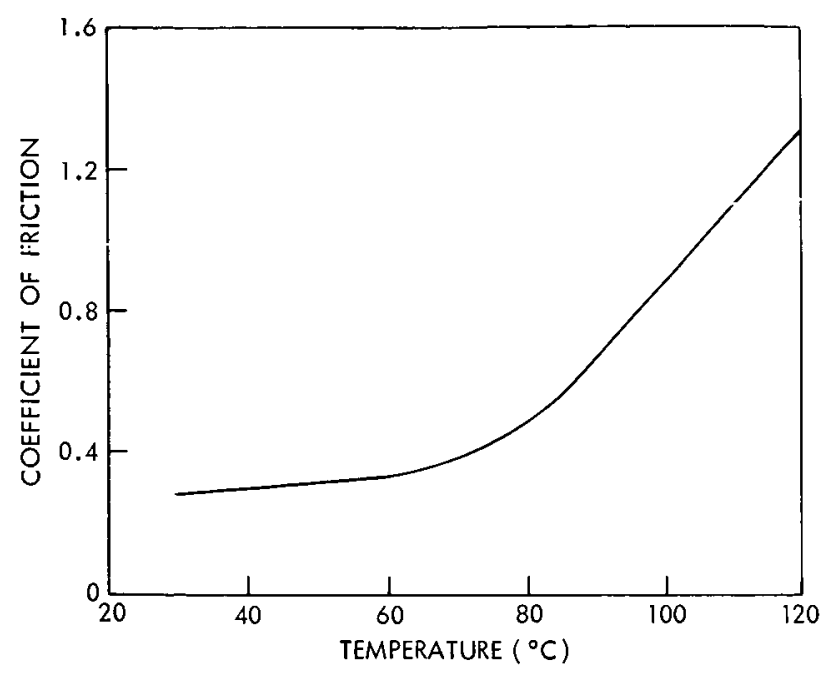

Figure $4 a-C o e f f i c i e n t$ of static friction versus temperature for polyester film against polyester film.

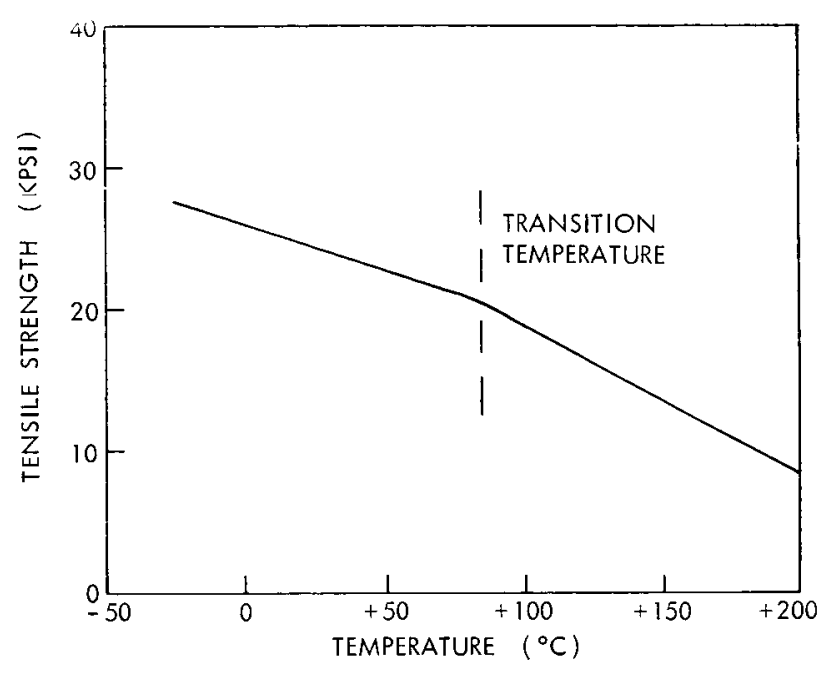

Figure $4 b-T e n s i l e$ strength versus temperature for same polyester film as in Figure $4 a$.

Figure 5 represents a commercially available instrumentation magnetic tape. The tape was tested in the conditions of (a) oxide against backing and (b) oxide against aluminum. Note the profile difference for the two conditions. The oxide-to-backing curve displays a very high peak at $75^{\circ} \mathrm{C}$ which is assumed to be caused by the binder material. Also, it is noted that in the region of $100^{\circ} \mathrm{C}$ to $120^{\circ} \mathrm{C}$ the curve is very similar to the polyester film-to-film curve.

Figure 6 shows the results of a second commercial instrumentation tape. Note the leveling off of the friction between $100^{\circ} \mathrm{C}$ and $120^{\circ} \mathrm{C}$. Visual inspection of this tape at elevated temperatures revealed that the oxide was very easily removed from the backing and had a dry powdery consistency.

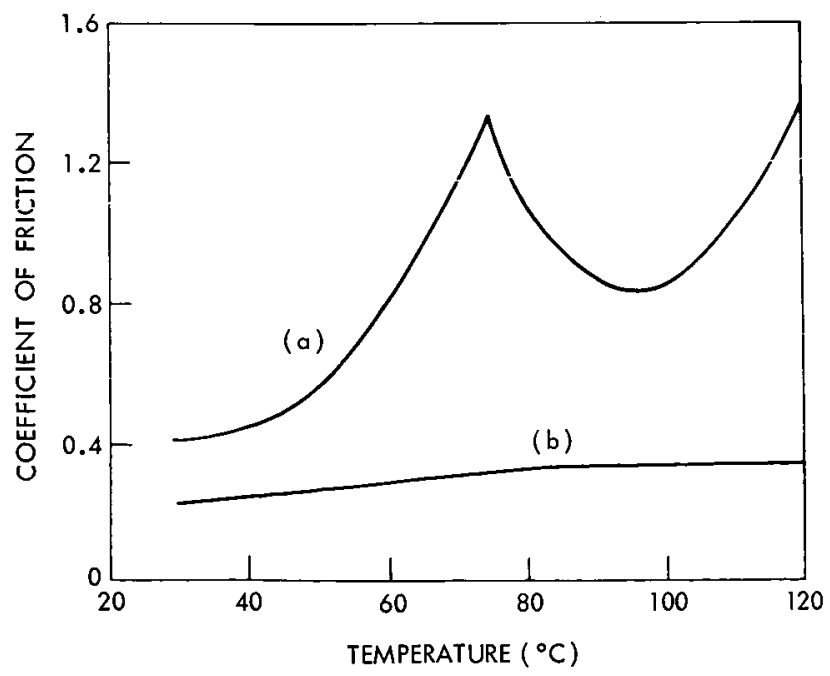

Figure 5-Commercial tape showing coefficient of static friction versus temperature for (a) oxide against backing and $(b)$ oxide against aluminum.

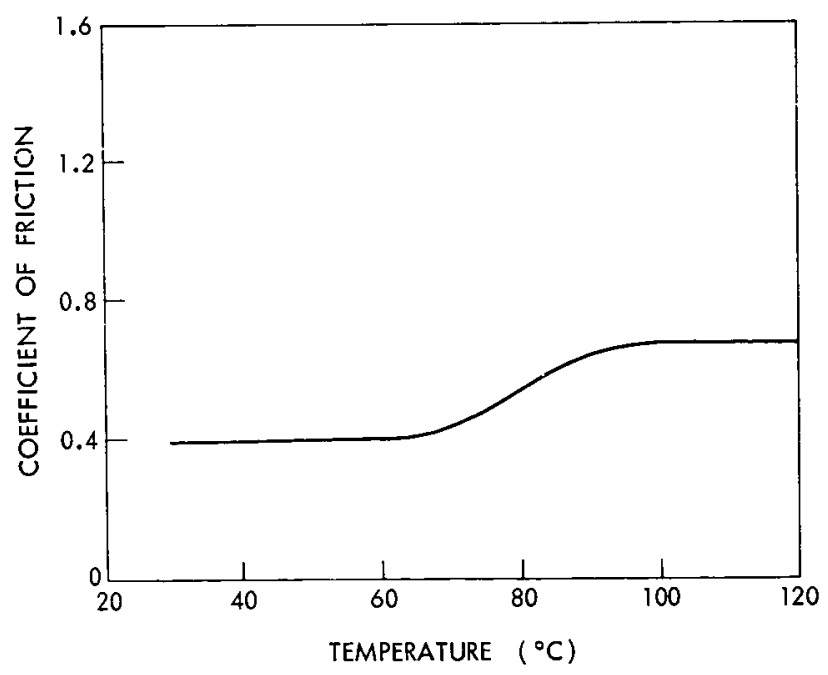

Figure 6-Commercial tape showing coefficient of static friction versus temperature for oxide against backing. 
Four different instrumentation grade tapes have been tested so far. They all display a distinct change in friction in the region of $55^{\circ} \mathrm{C}$ to $60^{\circ} \mathrm{C}$. In addition, the friction of all tapes when tested oxide to backing, increased at least 80 percent at $100^{\circ} \mathrm{C}$. These observations are believed to be very significant when related to our experience with endless-loop satellite recorders. It has been determined, by testing and operational practice, that reliable loop recorder operation can be maintained only when the ambient temperature is limited to $50^{\circ} \mathrm{C}$.

\section{CONCLUSIONS}

There is sufficient evidence from this initial effort to indicate that "static friction versus environment" testing will be a useful measure of the physical stability of magnetic tape and some other materials. This evidence does indeed support Clement's earlier conjecture. A detailed study and analysis of friction test results, and correlation with other physical parameters, are required to determine the full utility of the continuous test method.

A suitable, continuous static friction test device can be refined from this basic concept. The profiling of friction characteristics with reference to temperature and various atmospheric conditions can thereby be accomplished easily and routinely.

\section{ACKNOWLEDGMENTS}

Mr. Warren G. Clements' engineering objectivity and his inter-center cooperation greatly enhanced this extrapolation of his original work.

\section{REFERENCES}

1. Clement, W., "A Device for Measuring the Static Friction Between Magnetic Tape and Heads," in Space Programs Summary, Jet Propulsion Laboratory Report No. 37-33, Vol. 4, June 30, 1963.

2. Seely, F. B. and Ensign, N. E., "Analytical Mechanics for Engineers" p. 134, 4th Edition, New York: John Wiley and Sons Inc., April 1955. 
"The aeronautical and space activities of the United States shall be conducted so as to contribute. . . to the expansion of human knowledge of phenomena in the atmosphere and space. The Administration shall provide for the widest practicable and appropriate dissemination of information concerning its activities and the results thereof."

- National aeronautics and Space Act of 1958

\section{NASA SCIENTIFIC AND TECHNICAL PUBLICATIONS}

TECHNICAL REPORTS: Scientific and technical information considered important, complete, and a lasting contribution to existing knowledge.

TECHNICAL NOTES: Information less broad in scope but nevertheless of importance as a contribution to existing knowledge.

TECHNICAL MEMORANDUMS: Information receiving limited distribution because of preliminary data, security classification, or other reasons.

CONTRACTOR REPORTS: Technical information generated in connection with a NASA contract or grant and released under NASA auspices.

TECHNICAL TRANSLATIONS: Information published in a foreign language considered to merit NASA distribution in English.

TECHNICAL REPRINTS: Information derived from NASA activities and initially published in the form of journal articles.

SPECIAL PUBLICATIONS: Information derived from or of value to NASA activities but not necessarily reporting the results of individual NASA-programmed scientific efforts. Publications include conference proceedings, monographs, data compilations, handbooks, sourcebooks, and special bibliographies.

Details on the availability of these publications may be obtained from:

SCIENTIFIC AND TECHNICAL INFORMATION DIVISION

NATIONAL AERONAUTICS AND SPACE ADMINISTRATION

Washington, D.C. 20546 